\title{
A MATRIZ TERRITORIAL DE TIMOR-LESTE: subsídios para análise dos conflitos territoriais entre 1974 e $1999^{1}$
}

\section{THE TERRITORIAL MATRIX OF TIMOR-LESTE: subsidies for analysis of the territorial conflicts between 1974 and 1999.}

\author{
LA MATRIZ TERRITORIAL DE TIMOR-LESTE: subsidios el \\ análisis inicial de los conflictos territoriales entre 1974 y 1999.
}

\author{
Aníbal do Rosário da Costa \\ Ministerio da Educacao do Timor-Leste \\ Instituto Nacional de Formacão e Desenvolvimento dos professores de Timor-Leste. \\ Mestre em Geografia pela Universidade Federal de Goiás \\ Rua: Matadouro-Dili Timor-Leste \\ Email: anibaldorosariodacosta@yahoo.com.br
}

\section{Resumo}

Este texto tem como objetivo discutir sobre alguns elementos da matriz territorial de Timor-Leste e sobre a resistência da invasão indonésia entre os anos de 1974 e 1999. Para tal, foram realizadas revisões bibliográficas, pesquisa documental e levantamentos de bases de dados geográficos que subsidiaram a elaboração de alguns mapas que foram elaborados no ArcGis 9.3. São apresentados elementos da matriz territorial de TimorLeste que consideram-se centrais na articulação das estratégias de invasão dos indonésios e, também, da resistência timorense. Foram identificados os aspectos da localização de Timor-Leste, de suas paisagens, sua hidrografia e geomorfologia, assim como, aspectos sobre a população timorense e sua distribuição no território. Pode-se concluir que os componentes da matriz territorial timorense tiveram funções centrais na definição dos primeiros lugares que foram invadidos pelos indonésios e, também, na definição dos lugares onde ocorreram os principais focos da resistência.

Palavras-Chave: Timor-Leste, matriz territorial, conflitos territoriais, invasão indonésia.

\begin{abstract}
This paper aims to conduct an initial discussion about some elements of territorial matrix of East Timor and the Indonesian invasion resistance between the years 1974 and 1999. To this end, we carried out literature reviews, archival research and surveys of geographic databases that supported the preparation of some maps that were produced in ArcGIS 9.3. Array elements are present land of East Timor that we consider central to the articulation of strategies of the Indonesian invasion and

\footnotetext{
1 Texto oriundo de pesquisa de mestrado do Programa de Pós-Graduação em Geografia da UFG, orientado pelo Prof. Dr. Eguimar Felício Chaveiro no âmbito do grupo de estudos Espaço, sujeito e existência e, viabilizado pelo Edital CAPES/CNPq PEC-PG - 2009.
} 
also the East Timorese resistance. We identified the aspects of the location of East Timor, its landscapes, its hydrology and geomorphology, as well as aspects of the Timorese population and its distribution in the territory. It can be concluded that the Timorese territorial matrix components had central roles in the definition of the first places were invaded by the Indonesians, and also the definition of the places where there were major focuses of resistance.

Keywords: East Timor, territorial matrix, territorial conflicts, the Indonesian invasion.

\section{Resumen}

Este documento tiene como objetivo llevar a cabo una primera discusión sobre algunos elmentos de la matriz territorial de Timor Oriental y la resistencia a la invasión indonesia, entre los años 1974 y 1999. Con este fin, llevamos a cabo revisiones de la literatura, la investigación en archivos y las encuestas de bases de datos geográficos para apoyar la preparación de algunos mapas que se produjeron en ArcGIS 9.3. Elementos de la matriz actual de la tierra son de Timor Oriental, que consideramos fundamental para la articulación de las estrategias de la invasión indonesia, y también la resistencia de Timor Oriental.Se identificaron los aspectos de la ubicación de Timor Oriental, sus paisajes, de su hidrología y geomorfología, así como los aspectos de la población de Timor-Leste y su distribución en el territorio. Se puede concluir que los componentes de la matriz territorial de Timor había un papel central en la definición de los primeros lugares fueron invadidos por los indonesios, y también la definición de los lugares donde había grandes focos de resistencia.

Palabras clave: Timor Oriental, la matriz territorial, los conflictos territoriales, la invasión indonesia.

\section{Introdução}

Este texto tem como objetivo discutir a matriz territorial de Timor-Leste na resistência contra a invasão da Indonésia. Faz parte também de uma reflexão mais ampla que possui como foco os conflitos territoriais ocorridos nesse país no decorrer dos anos de 1974 até 1999.

O povo ${ }^{2}$ timorense é o primeiro da recente história do século XXI a tornar-se independente. Timor-Leste é marcado pela colonização portuguesa que iniciou no começo do século XVI e teve fim em 1974 com o desencadeamento do processo de descolonização português. No entanto, apesar de inserido em um processo mais amplo de descolonização portuguesa, ao contrário do que ocorreu em colônias como Moçambique, Angola e Guiné-Bissau, na África, em Timor-Leste não existiam

\footnotetext{
${ }^{2}$ No caso deste texto, empregamos o uso da expressão "povo timorense" nos referindo a todas as tribos que se situam dentro do território de Timor-Leste; não desconsiderando, no entanto, as diferenças étnicas, culturais e ideológicas dessa população.
} 


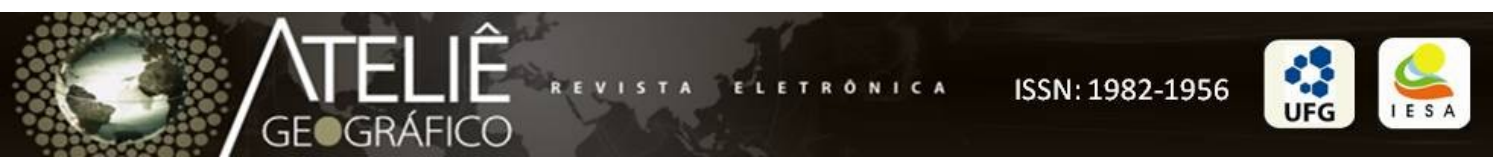

movimentos pró-independência.

A situação de Timor-Leste enquanto colônia portuguesa teve como peculiaridade em relação a outras colônias um relativo "descaso" de Portugal, que durante mais de quatro séculos não efetivou uma verdadeira economia colonial e não implementou de fato uma política de povoamento, o que acarretou em pouquíssimas alterações no modo de vida tradicional da maior parte da população, (CUNHA, 2001).

Assim, pode-se entender pelo menos um dos motivos que levaram a ausência de movimentos pró-independência em Timor até o ano de 1974: com alguns membros da elite timorense envolvidos na administração direta do território e a não interferência em seus modos de vida, a população não despertava interesse em se desvincular de Portugal.

Durante a ocupação portuguesa os timorenses se dividiam em diversos grupos tribais que, mesmo sendo vassalos de Portugal, mantinham sua autonomia até o começo do século XX. A presença da coroa portuguesa restringia-se na figura de um único governador em Dili, capital do Timor.

O território de Timor-Leste localiza-se em uma ilha dentro do arquipélago que compõe a Indonésia. Situa-se entre a Ásia e a Austrália, (fig. 1). O recorte de seu território é fruto de disputas entre Portugal e Holanda para a fixação de froteiras. Pelo Tratado de 1851 entre os países baixos, Portugal cede Flores e Solor e, recebe Maubara e mais uma quantia em dinheiro da Holanda, dando origem as atuais fronteiras políticoadministrativas de Timor. As disputas entre holandeses e portugueses deram origem a uma ilha dividida em Timor-Leste, de colonização portuguesa e, em Timor-Oeste, de colonização Holandesa, atualmente território indonésio. 


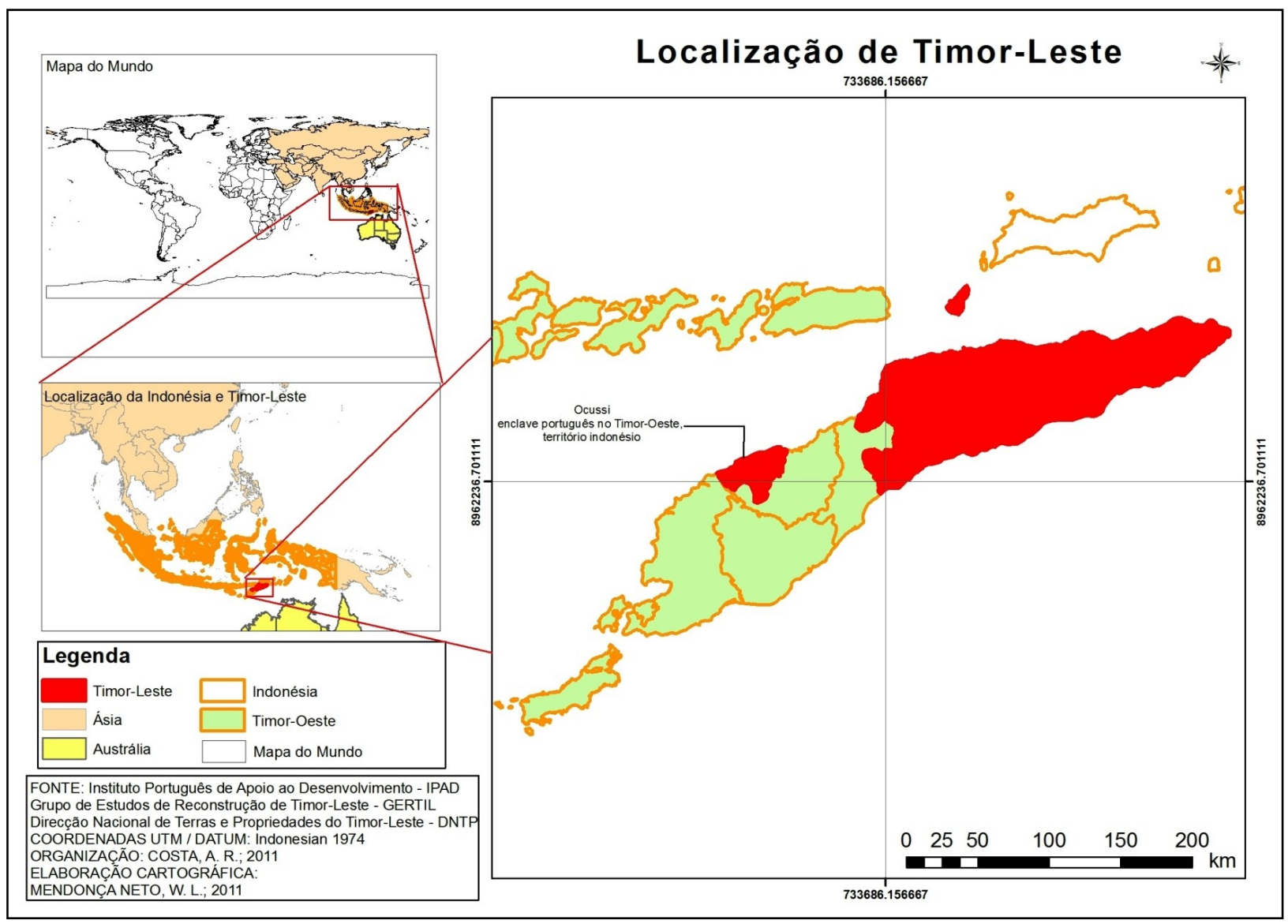

Figura 1 - Mapa de localização de Timor-Leste

Depois de quatro séculos de ocupação portuguesa sem muitas interferências nos modos de vida tradicionais dos timorenses, a não ser algumas poucas relações econômicas relacionadas principalmente com a extração de madeira, e o estabelecimento de um relativo conforto entre a colônia e a metrópole em termos administrativos; com o desencadear da Revolução dos Cravos em Portugal, em 25 de abril de 1974, inicia-se em Timor-Leste a organização dos primeiros partidos políticos.

A constituição das bases ideológicas e, portanto, político-partidárias em conjunto com os elementos da matriz territorial de Timor-Leste, entendida aqui como o conjunto dos elementos físicos, sociais e culturais do território, compuseram a possibilidade dos Maubere resistir à invasão da Indonésia. Diante disso, a questãoproblema é: Qual foi o papel dos elementos da matriz territorial timorense, principalmente o relevo, para a resistência? No próximo tópico apresentaremos primeiro alguns aspectos das paisagens timorenses e, posteriormente, aspectos de seu suporte físico territorial. 


\section{Paisagens Timorenses e componentes da matriz territorial}

A localização geográfica de Timor-Leste, (fig.1), e sua constituição geológica, favoreceram a formação de paisagens únicas nesse território. Timor-Leste é banhado pelos oceanos Índico e Pacífico e possuí cerca de $14.874 \mathrm{Km}^{2}$. Em suas paisagens é marcante o contraste entre as praias do litoral e o relevo montanhoso no interior do país (fig. 2). Pode-se identificar, a partir das concepções de Santos (1991), que a paisagem não somente revela o universo natural do território, mas, também, revela e contrasta com o mundo de coisas construídas, artificializadas. Dessa forma, pode-se perceber nas paisagens de Timor-Leste as praias e as formações rochosas constrastando com a projeção do trabalho humano no espaço, como as casas típicas e os campos de arrozal.

As montanhas em Timor-Leste são um aspecto importante para o estabelecimento dos modos de vida da população timorense. Como pode ser observado na figura 2, elas estão presentes em todas as oito fotografias, que são um esforço de ilustrar a diversidade das paisagens timorenses ao longo de sua extensão territorial. No decorrer deste trabalho, será ressaltada a importância do relevo de Timor-Leste e suas cadeias montanhosas para a resistência contra a invasão Indonésia. 


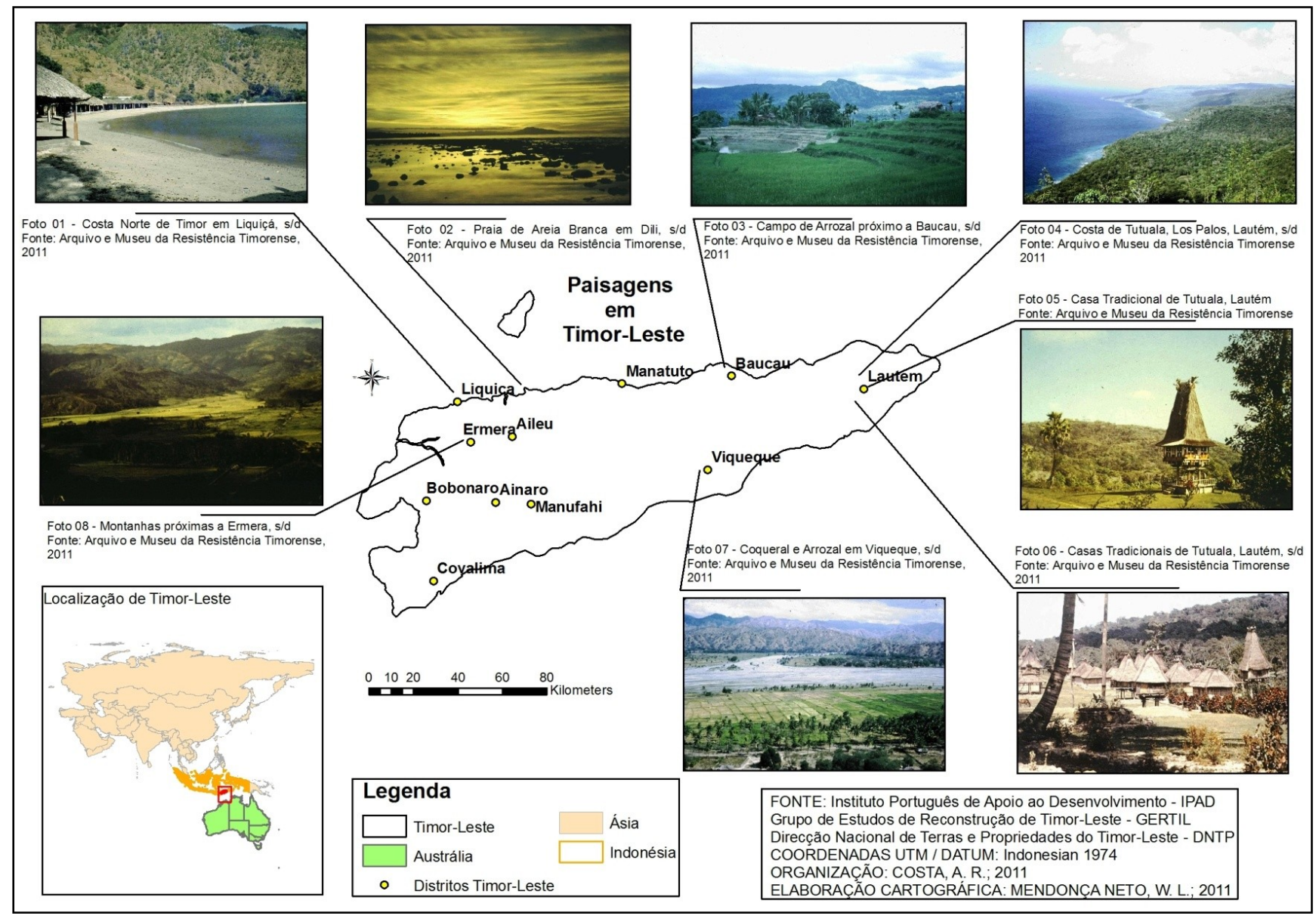

Figura 02 - Paisagens no Timor-Leste.

Fonte: Arquivo e Museu da Resistência Timorense.

As cotas altimétricas em Timor-Leste variam do nível do mar até dois mil setecentos e cinquenta metros (fig. 3). Pode-se identificar três grandes formações rochosas em Timor, na parte oeste, mais próximo a fronteira terrestre com a Indonésia, na parte central de Timor e, também, na parte leste. As três formações serviram de abrigo aos refugiados e de suporte a bases militares do exército da resistência timorense.

As formações rochosas também têm um papel fundamental na composição da rede hidrográfica de Timor. Como pode ser observado na figura 3, os principais rios timorenses são oriundos de nascentes desses complexos montanhosos.

Os recursos hídricos que compõe Timor-Leste e que possuíram papel importante para a resistência timorense são o Rio Namaluto, na parte sudeste da ilha, Ribeirão Laivai, Ribeirão Boro Uai, na parte nordeste, Ribeirão Lacló, Ribeirão Sumasse e Ribeirão Laléia, na parte norte, Ribeirão Dilor, Ribeirão Lacló do Sul e Ribeirão Caráulum, na parte sul, Ribeirão Tafara na parte sudoeste e, Ribeirão de Lois na parte

Ateliê Geográfico Goiânia-GO v. 6,n.1 abr/2012 $\quad$ p.01-17 Página 6


noroeste.

Estes cursos d'água foram destacados devido a importância estratégica para a resistência timorense. Não somente no contexto da guerrilha esses recursos hídricos foram importantes, mas, também, a fixação de vários povoados e aldeias em TimorLeste ocorreu a partir da disposição dos leitos desses rios. Observe na figura 4 que a concentração de povoados segue o sentido da concentração dos rios e, também, o de concentração das principais rodovias (fig. 07).

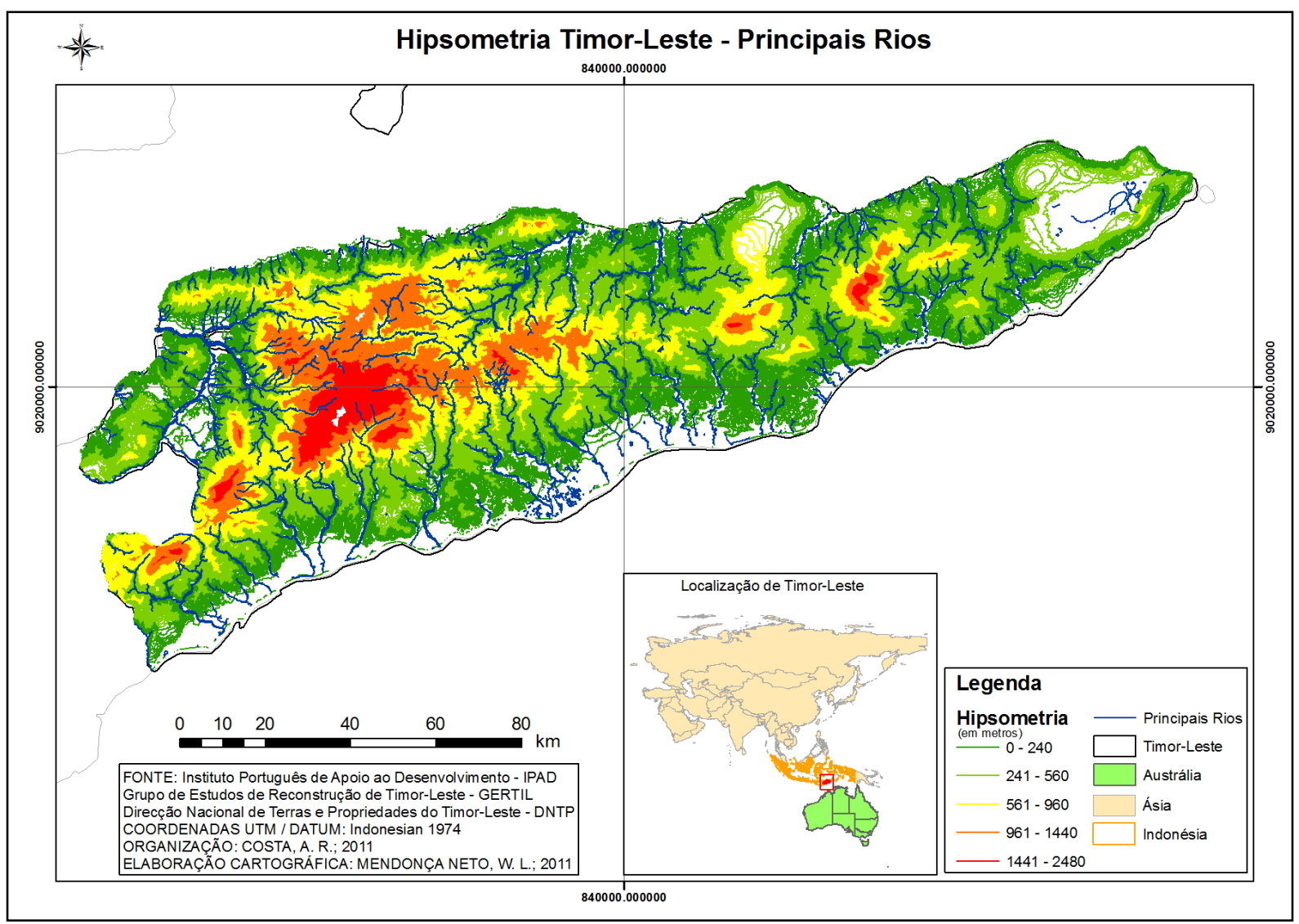

Figura 03 - Mapa hipsométrico de Timor-Leste - destaque para os principais rios. 

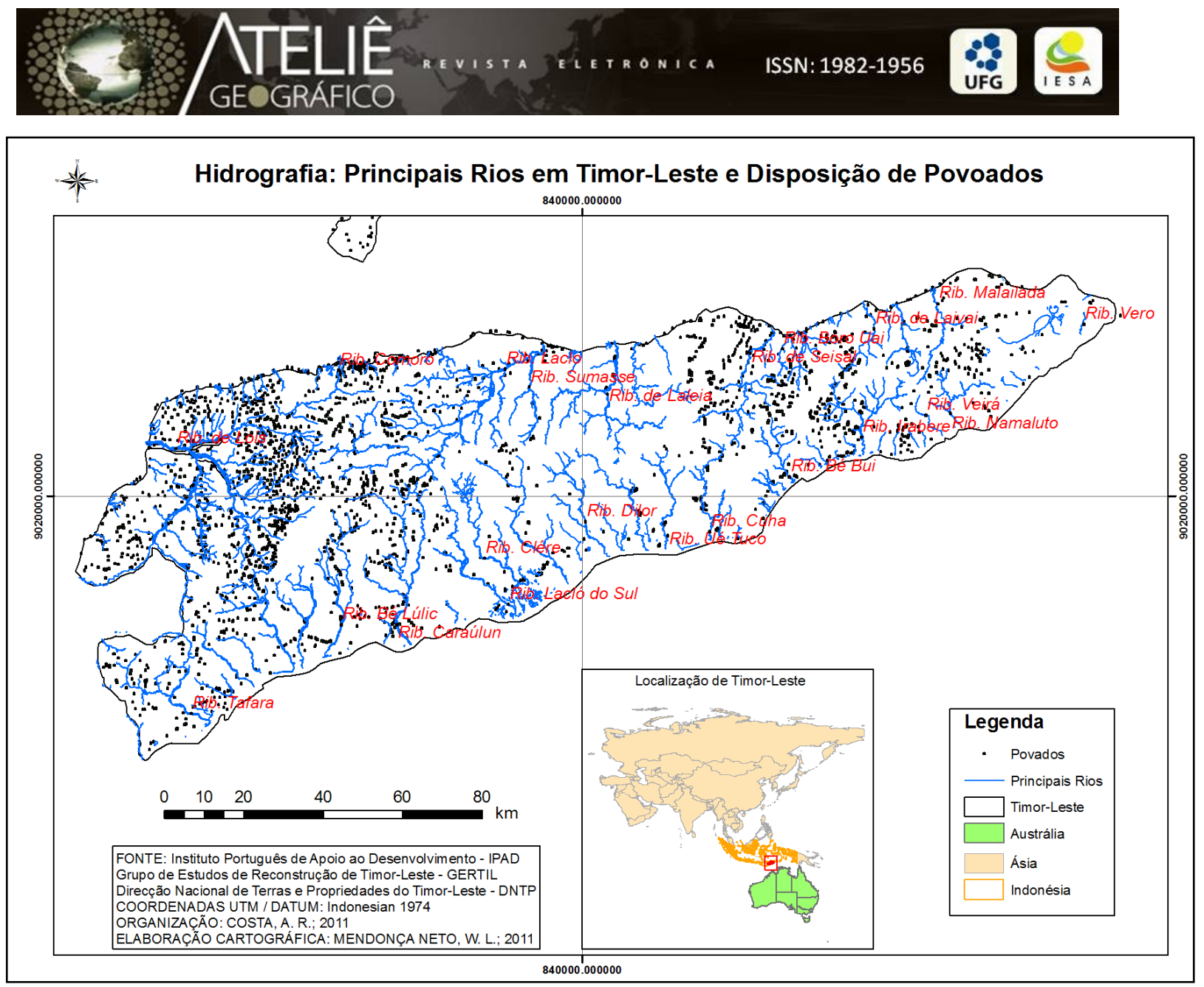

Figura 04 - Mapa da hidrografia e da disposição de povoados em Timor-Leste.

Pode-se destacar, de acordo com a importância para resistência dos timorenses, os montes Ramelau, Balibó, Manufai, Cablaque e Cailaco, na parte oeste, o monte Perdido, na parte central, assim como o complexo de montanhas conhecidas como Matebean, formado pelos montes, Ulgata, Aububu, Boicau, Ve-Sabu, Malabia e LoiLari (fig. 05).

Os Montes enunciados tiveram papel central na articulação tanto de estratégias de invasão do exército indonésio, quanto para as táticas de resistência dos grupos de guerrilheiros do Timor-Leste. A Indonésia começou o processo de avanço de suas tropas primeiro pelo lado oeste da ilha, onde se localizam suas fronteiras com as timorenses e, também pelo litoral, onde ficam os principais distritos.

Esse movimento de invasão indonésia empurrava os guerrilheiros e, também milhares de refugiados, na direção sudeste da ilha. Dessa forma, a grande primeira resistência dos timorenses se deu junto ao conjunto de montanhas a oeste de Timor, principalmente no Monte Ramelau, Cablaque e Balibó. O segundo local em importância 
estratégica de resistência da guerrilha timorense foi a região que compreende o Monte Perdido e a cadeia de montanhas conhecida como Matebean.

Segundo análise das informações pesquisadas sobre o movimento de invasão do exército indonésio e, da resistência timorense, praticamente todos os pontos do relevo foram, em algum momento dos conflitos, suporte físico dos confrontos. As formas de relevo destacadas também possuíram papel especial devido ao fato de terem fomentado algo mais forte que os fuzis e todo o aparato bélico; desses marcos geográficos, surgiram gestos simbólicos, atos de profunda determinação em resistir. Nesses montes citados de forma destacada, alguns poucos sujeitos, incluindo mulheres e crianças, Resistiram. Nesses lugares derrotaram centenas de indonésios. Companhias inteiras da Indonésia, compostas por cerca de 90 homens em média, armados com equipamentos de guerra fornecidos pelos EUA, (COLARES, 2006), eram derrotados por minorias de pessoas que contavam com a ástucia de conhecer o terreno da guerra, com a criatividade e, a "Catana", uma espécie de faca timorense, símbolo da guerra e de bravura.

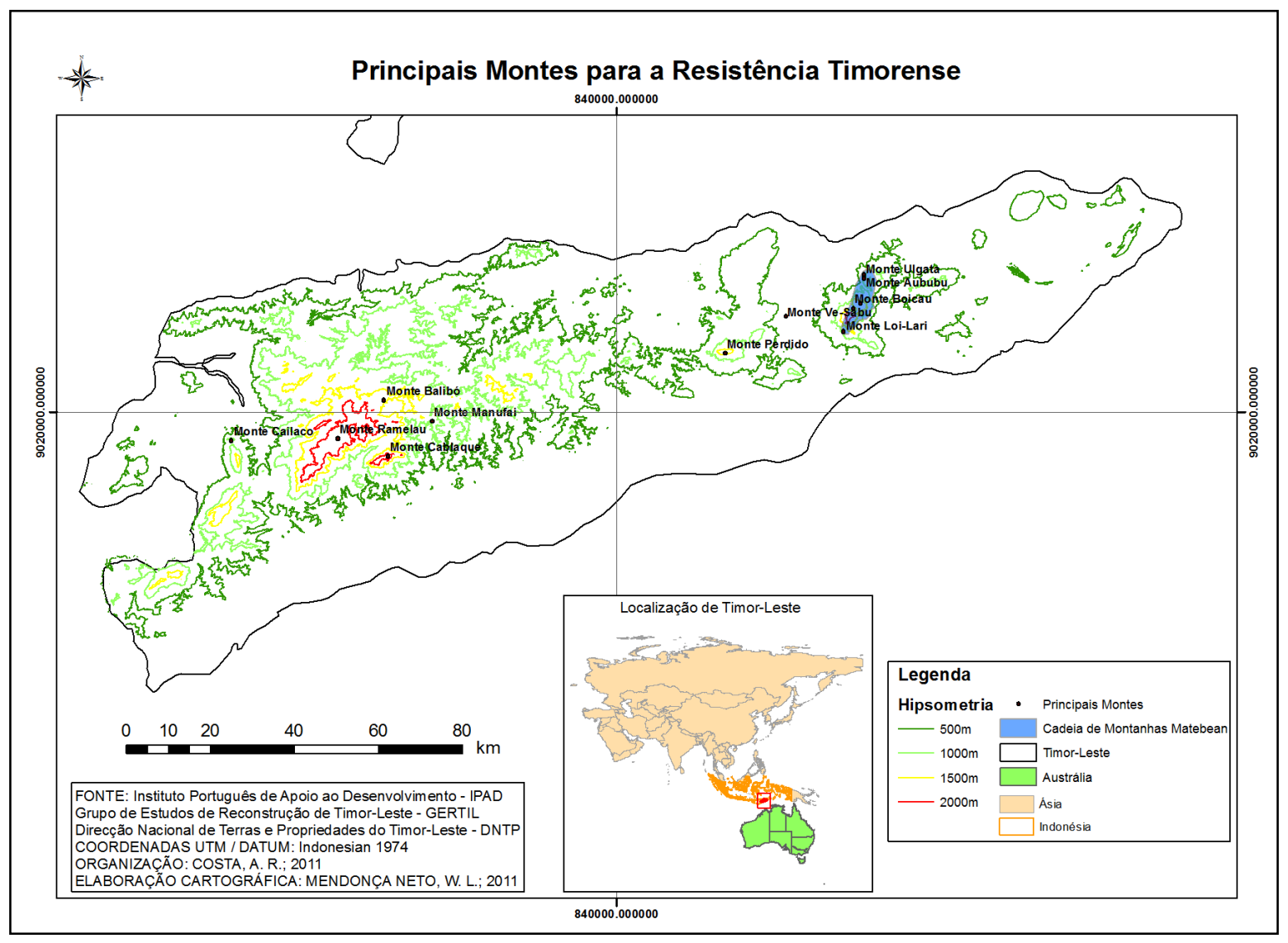

Figura 05 - Principais Montes para a Resistência Timorense. 
O subsolo do território timorense, além de ser o suporte para a cadeia de montanhas que, como identificado anteriormente, teve papel importante na elaboração de estratégias nos anos dos conflitos, também guarda alguns dos motivos que alimentaram o interesse dos Indonésios em integrar Timor-Leste.

Segundo as Nações Unidas, (Atlas de Recursos Minerais, 2003), no subsolo de Timor-Leste ocorrem diversos tipos de minérios, entre eles, hidrocarbonetos que possuem potencial de exploração de petróleo e gás natural (fig. 06). A exploração dos derivados de hidrocarbonetos só é economicamente viável na parte sul devido as condições climáticas e geomorfológicas.

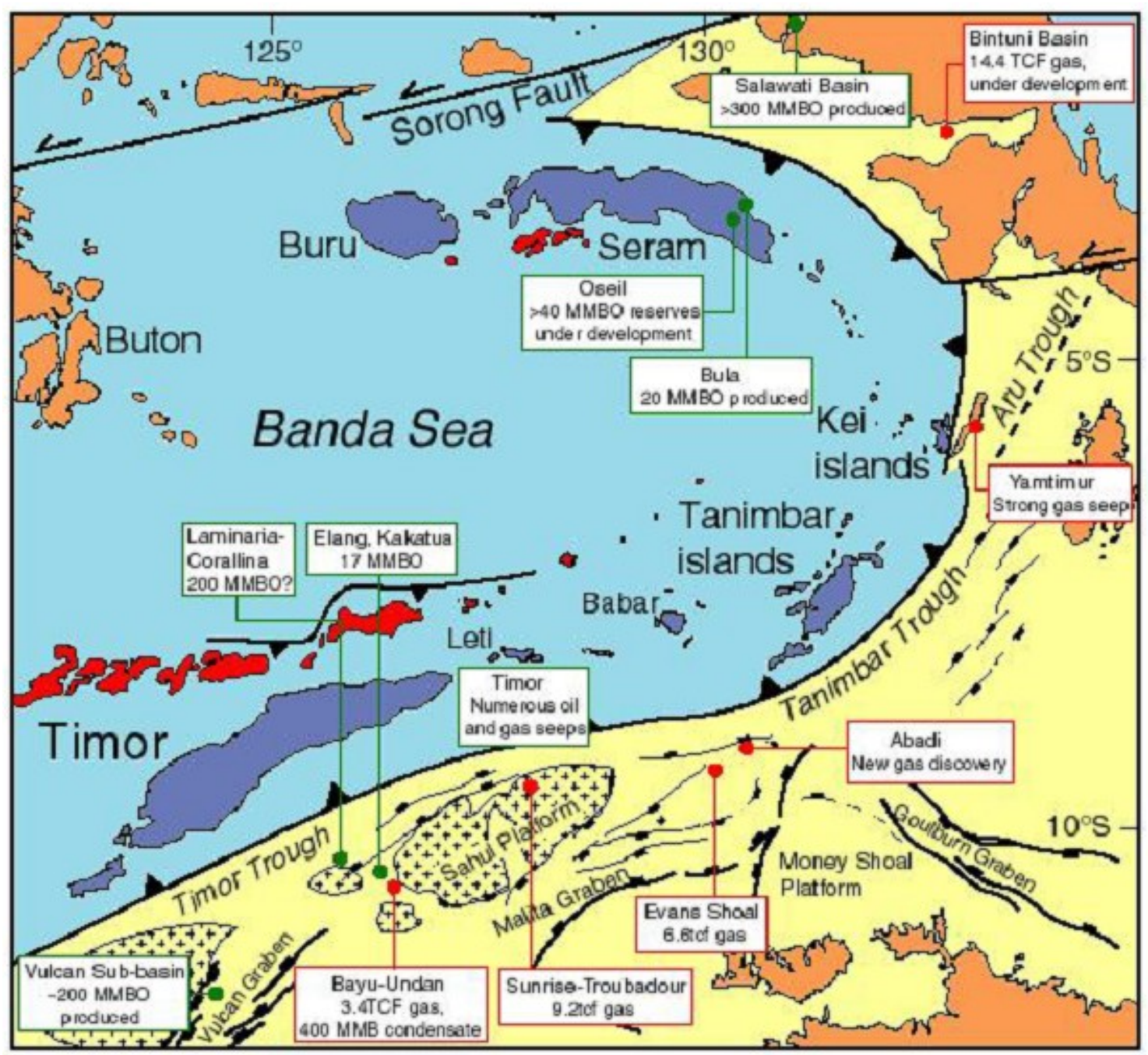

Figura 06 - Áreas potenciais para extração de petróleo e gás natural.

Fonte: Atlas of Mineral Resources of the Escap Region. Vol. 17. Geology and Mineral Resources of Timor-Leste (2003). 
Ainda Segundo esse mesmo atlas, também existem em Timor-Leste diversos minérios que podem se utilizados para a fabricação de materiais de construção como mármore, areia e cascalho, algumas reservas de pedras preciosas como diamantes, entre outros.

A organização da rede viária de Timor-Leste é totalmente adaptada ao tipo de relevo. As principais rodovias que realizam a conexão entre os distritos são, em sua maioria, construídas em baixas e médias altitudes (fig. 07), contornando o relevo acidentado. Dessa forma, esses acessos situam-se nos sopés das montanhas. Essa situação foi fundamental para a elaboração das estratégias de guerra e de guerrilha.

Se por um lado, o exército da Indonésia procurava bloquear os acessos mais importantes entre os principais distritos de Timor-Leste, por outro lado, ao proceder dessa forma, se tornavam alvos vulneráveis devido a fácil visibilidade dos guerrilheiros situados em posições estratégicas, privilegiadas pelas altitudes, nas montanhas.

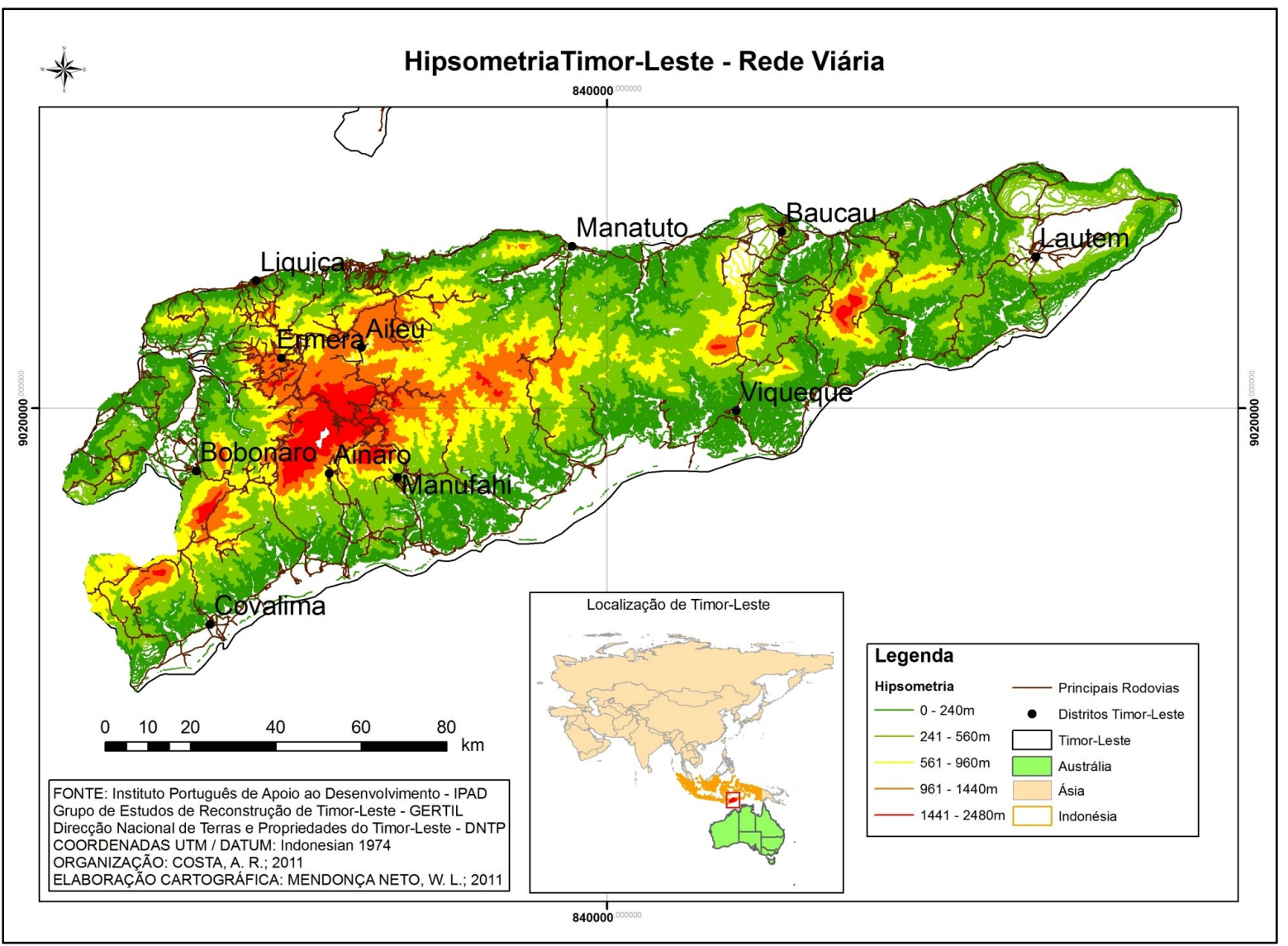

Figura 07 - Mapa Hipsométrico de Timor-Leste com destaque para as principais rodovias. 
Segundo as Nações Unidas, (Atlas de Recursos Minerais, 2003), as pricipais rodovias de Timor-Leste se concentram na costa norte, onde, também, estão as regiões mais importantes política e administrativamente. As rodovias do sul se encontram mal preservadas e, na maioria dos trechos, somente são acessíveis a veículos com tração 4X4. Apesar de serem contabilizadas 450 pontes, a maioria foi destruída durante os anos da invasão indonésia e não estão em condições de uso.

Os consecutivos anos de resistência timorense, no entanto, acabaram por imprimir no território diversos outros caminhos alternativos aos acessos das principais rodovias que, como parte de estratégias de guerra, muitas vezes se encontravam bloqueadas pelas tropas indonésias. Não somente os inúmeros trajetos traçados cortando as montanhas como rotas alternativas as estradas principais, mas, também, a grande dispersão das populações pelas regiões montanhosas indica uma diáspora dos timorenses das principais cidades. Ainda hoje, cerca de $85 \%$ da população vive em povoados longe dos centros urbanos (fig. 08).

Contudo, a maior concentração populacional está no município de Dili, capital de Timor-Leste. A divisão administrativa de Timor é organizada a partir de seus distritos e seus sub-distritos. Dili é um distrito e, em conjunto com seus sub-distritos, compõe uma região administrativa denominada de município.

Segundo a Lei da Divisão Adminstrativa e Territorial da República Democrática de Timor-Leste, o "território de Timor-Leste divide-se em pessoas coletivas de território, denominadas municípios, sendo que cada um destes compreende uma unidade de poder local". A definição de município envolve a noção de um coletivo humano, um território, que possui autonomia administrativa e financeira, órgãos representativos eleitos democraticamante. Cada distrito é constituído de sub-distritos que, juntos, compõem um município. 


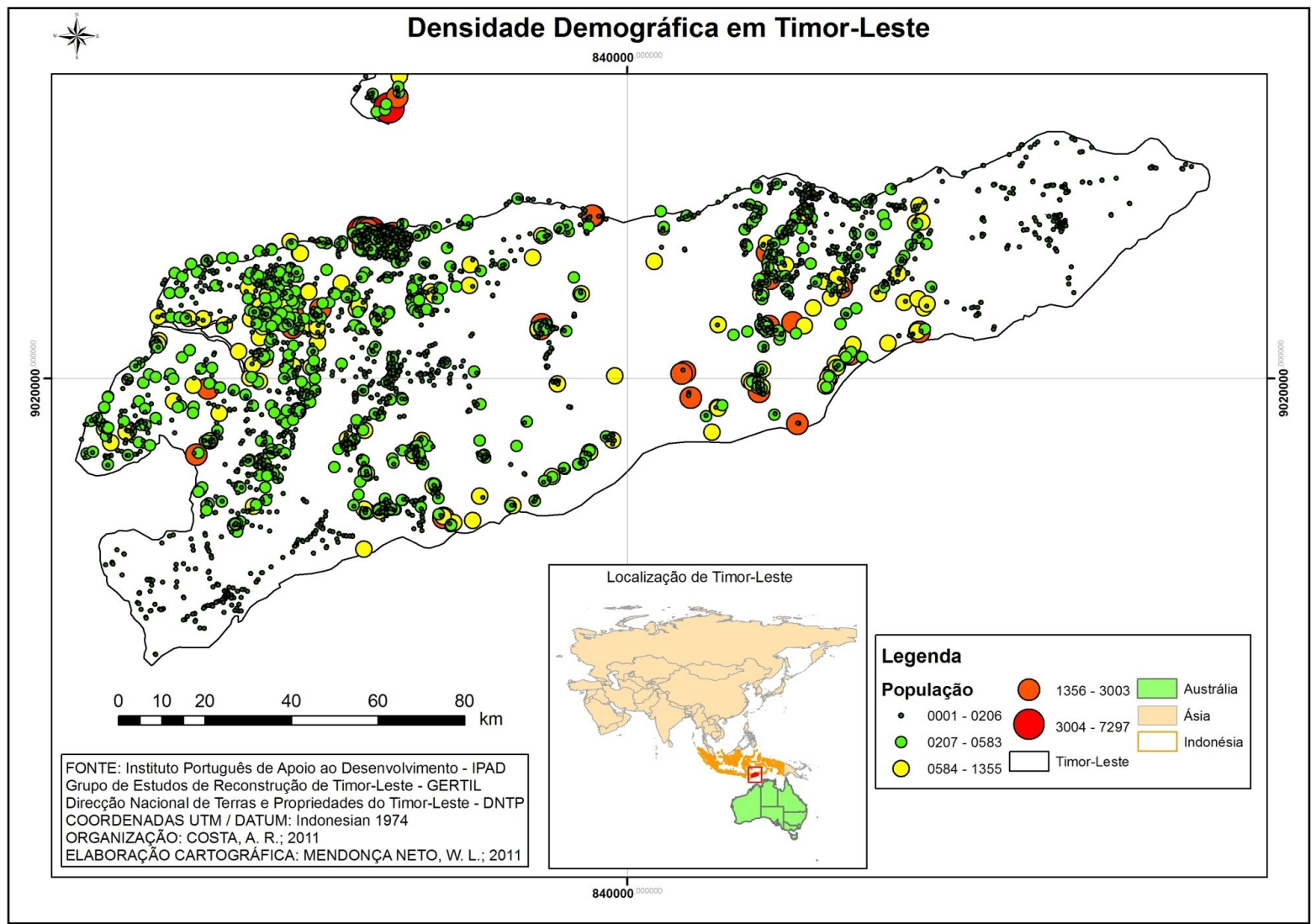

Figura 08 - Mapa da densidade demográfica em Timor-Leste.

A população timorense possui matriz étnica constituída por processos de miscigenação entre os aborígenes australianos, os papuans e os malaio-polinésios. Esse processo de hibridização resultou em um biotipo de pele parda-escura, cabelos lisos, estatura mediana e olhos repuxados. Dos austronésios, além do tipo físico predominante, também herdaram algumas das principais línguas faladas em TimorLeste, como o Tetum e o Baikenu.

Nos anos precedentes da invasão indonésia, a população timorense vivia dispersa pelos mais de 30 Sulcos existentes, uma espécie de domínio político e administrativo tradicional. Ainda hoje a densidade demográfica nas diversas localidades é muito baixa, a maioria dos povoados possuem populações menores do que 500 habitantes. As maiores populações estão em Dili, Masilihu, Manatuto, Hatoposi, Falimano, Loblata, Marko, Dilor, Umatolu, Viqueque, Ossu, Daesi, Queloborouai, Venilale, Lassorolai e Borolalo.

Até 1974, devido a política de colonização portuguesa em Timor-Leste ressaltada no tópico anterior, a população timorense vivia em consonância com a cultura 


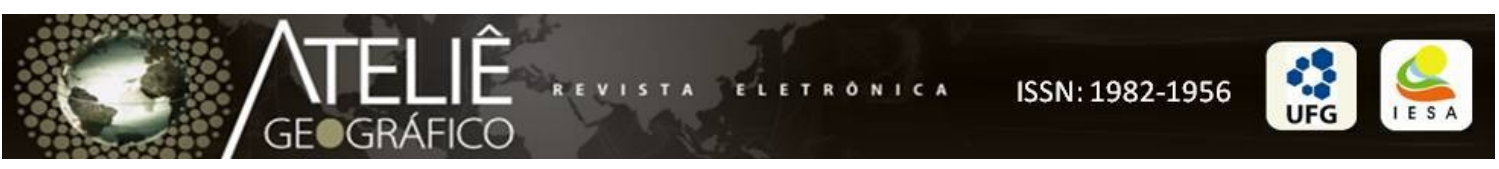

tradicional. A partir dessa data, sob a emergência da descolonização, da formação confusa e tumultuada dos partidos políticos em Timor que, sem uma tradição democrática e em processo de disputa de poder, não se entendiam sobre o futuro do território e, na possibilidade de invasão da Indonésia, as comunidades tradicionais passaram a ir a comícios, (fig. 09), tendo que, às pressas, se organizar na forma de uma "República Democrática".

Em outras palavras, tiveram que fazer política de uma outra forma, nos termos, agora, do mundo globalizado. O mundo agora estava mais do que nunca em Timor e, em lugares onde os portugueses não haviam chegado na dimensão simbólica do ser timorense.

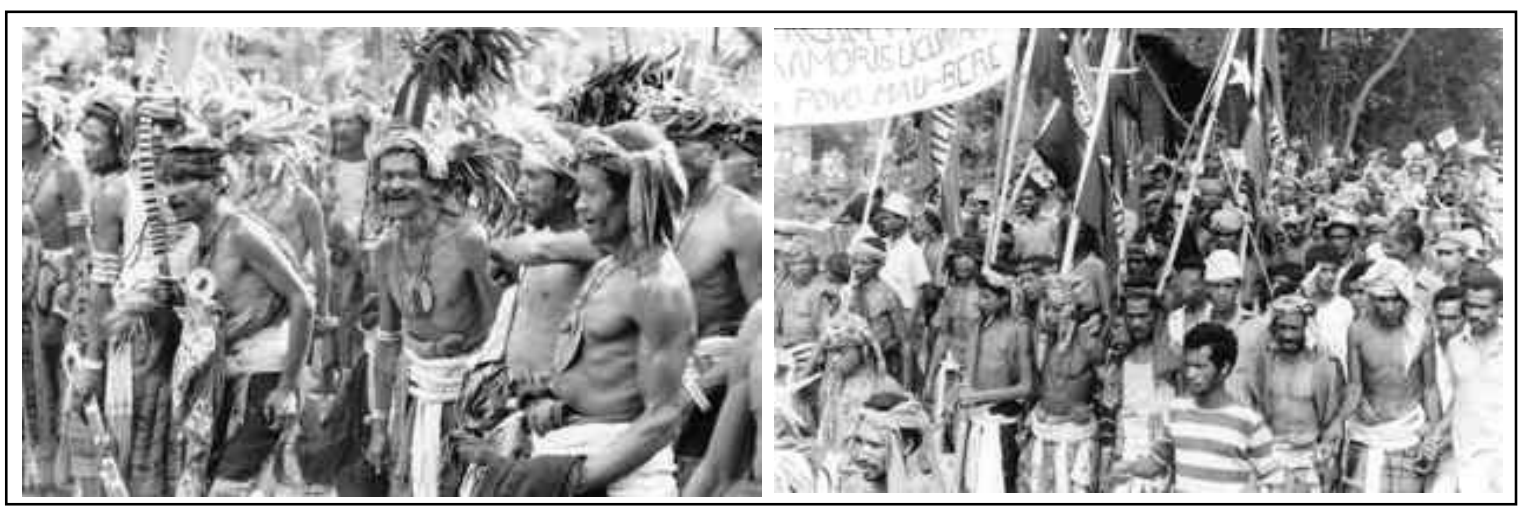

Figura 09 - Comunidades tradicionais em comício nos anos de 1974.

Fonte: Arquivo e Museu da Resistência Timorense.

A constituição de um sistema-mundo moderno-colonial, (WALTER, 2006; e PORTO-GONÇALVES), no fim do século XX, principalmente em 1974, despertou o timorense da dormência dos períodos de colonização portuguesa.

\section{Considerações finais}

Este texto teve o objetivo de apresentar alguns elementos da matriz territorial de Timor-Leste com a finalidade de que esses elementos possam subsidiar análises relacionadas aos conflitos territoriais ocorridos nesse país entre os anos de 1974 e 1999. Para tal, foram realizadas revisões bibliográficas, pesquisa documental, levantamentos de bases de dados geográficos que subsidiaram a elaboração dos mapas que foram elaborados no ArcGis 9.3.

Para atingir o objetivo proposto, apresentamos elementos da matriz territorial de 
Timor-Leste que consideramos centrais na articulação das estratégias de invasão dos indonésios e, também, da resistência timorense. Foram identificados os aspectos da localização de Timor-Leste, de suas paisagens, sua hidrografia e geomorfologia, assim como aspectos sobre a população timorense e sua distribuição no território.

A análise dos componentes da matriz territorial de Timor-Leste permite entender com mais clareza o verdadeiro interesse dos indonésios na invasão e, também, a lógica das estratégias de guerra e de guerrilha. A invasão indonésia ocorreu mediante a consideração desses componentes da matriz territorial. A definição dos primeiros locais a serem invadidos e dominados foi considerado a partir de seus contingentes populacionais e, também, pelas possibilidades de acesso. Porém, a definição das localidades de resistência foram consideradas pelas localizações estratégicas, seja devido as características de relevo, seja devido a existência de contingentes dispostos a resistir.

A análise dos resultados obtidos, no que diz respeito à relação entre a matriz territorial, a invasão da Indonésia e a resistência Timorense, nos permitem chegar as seguintes conclusões:

1. A Indonésia planejou a invasão de Timor-Leste a partir das cidades que possuem fronteiras terrestres, localizadas na parte oeste e, também, a partir das principais cidades timorenses localizadas na costa norte de Timor;

2. As cidades da costa norte de Timor-Leste são as que possuem os maiores contingentes populacionais que, com o desencadear da invasão, iniciam um processo de migração em massa para as montanhas do hinterland timorense;

3. Os três grandes conjuntos montanhosos de Timor-Leste, a oeste, principalmente os Montes Balibó, Ramelau e Callaco, na parte central, o Monte Perdido e, a leste a cadeia de montanhas conhecida como Matebean, tiveram papel fundamental para a resistência na medida em que funcionou como refúgio e esconderijo para a elaboração de estratégias de guerrilha.

É pertinente, no entanto, que se faça a seguinte consideração: o conhecimento de alguns dos elementos da matriz territorial de Timor-Leste é um primeiro passo para uma análise mais completa que, deve se debruçar sobre processo que animou o suporte físico-territorial timorense ao longo dos anos dos conflitos territorias. Nesse sentido, ao presente trabalho entendemos que deve-se somar uma leitura das condições geopolíticas 
mundiais e as forças que atuaram localmente em Timor.

\section{Referências bibliográficas}

CUNHA, João Solano Carneiro. A questão de Timor-Leste: origens e evolução. Brasília, FUNAG, 2001.

COLARES, Luciano da Silva. As missões de paz da ONU e a questão de TimorLeste: ponto de inflexão? Dissertação apresentada na UFRS, em Porto Alegre, 2006.

ALMEIDA, Maria Geralda. As ambiguidades do ser ex-migrante: o retorno e o viver entre territórios. In: ALMEIDA, MARIA GERALDA. Territorialidades na Améria Latina. Goiânia: UFG/Funape, 2009.

HASBERT, Rogério; PORTO-GONÇALVES, Carlos Walter. A nova des-ordem mundial. São Paulo: Unesp, 2006.

PELÁ, Márcia Cristina Hizim; CHAVEIRO, Eguimar Felício. Sujeitos não desejados no espaço planejado: disputa de territorialidades na costrução de Goiânia, Go. In: ALMEIDA, Maria Geralda. Territorialidades na Améria Latina. Goiânia: UFG/Funape, 2009.

RAFFESTIN, Claude. Por uma Geografia do Poder. Editora Ática, São Paulo, 1993.

SANTOS, Milton. A Natureza do Espaço. São Paulo: Edusp, 2009.

SANTOS, Milton. Metamorfoses do Espaço Habitado: fundamentos teóricos e metodológicos da Geografia. São Paulo: Editora Hucitec, 1991.

SANTOS, Milton. Por uma Geografia Nova. São Paulo: Edusp, 2008.

SAQUET, Marcos Aurélio. Abordagens das dimensões sociais do território. In: ALMEIDA, Maria Geralda. Território e Cultura: Inclusão e exclusão nas dinâmicas 
socioespaciais. Goiânia: UFG/Funape, 2009.

SPÓSITO, Eliseu Savério. Geografia e filosofia: contribuições para o ensino do pensamento geográfico. São Paulo: Unesp, 2004.

ORGANIZAÇÃO DAS NAÇÕES UNIDAS. Atlas of Mineral Resources of the Escap Region. Vol. 17. Geology and Mineral Resources of Timor-Leste. Economic and Social Commission for Asia and the Pacific. UN: New York, 2003.

WALDMAN, Maurício. Em Timor-Leste, a luta continua! Artigo publicado na seção do Boletim Semanal Véspera, n²47, Março de 1993, página 9, Agência Ecumênica de Notícias (AGEN), São Paulo, SP, 1993.

Recebido para publicação em outubro de 2011 Aprovado para publicação em janeiro de 2012 